\title{
FEVEREIRO TEM CARNAVAL? POLÍTICAS PÚBLICAS PARA O SETOR DE TURISMO EM PERNAMBUCO DECORRENTES DA PANDEMIA DA COVID-19
}

\author{
DO WE HAVE CARNAVAL IN FEBRUARY? COVID-19-RELATED PUBLIC POLICY TARGETING TOURISM IN \\ PERNAMBUCO
}

\author{
¿EN FEBRERO HAY CARNAVAL? POLÍTICAS PÚBLICAS PARA EL SECTOR TURÍSTICO EN PERNAMBUCO A RAÍZ DE LA \\ PANDEMIA DE COVID-19
}

\section{RESUMO}

Esse artigo tem por objetivo avaliar como o Estado de Pernambuco, por meio de suas políticas públicas, tem enfrentado a pandemia de COVID-19 em relação ao setor de turismo. Para tanto, traz um panorama do impacto da pandemia, considerando o primeiro semestre de 2020, nas contas públicas, no fluxo aéreo, nos meios de hospedagem e na empregabilidade, tendo como fontes de dados os portais da transparência e demais informações de caráter público emanadas pelos governos federal e estadual. A criação do Comitê Científico do Nordeste e suas recomendações para o enfrentamento da pandemia são cotejados no sentido de se estabelecer a adoção (ou não) de tais diretrizes para a consecução de decretos estaduais direcionados ao combate à pandemia. Intenta-se salientar como o Estado de Pernambuco busca administrar a crise, pesando os dois lados da balança: as recomendações do Consórcio e a pressão do setor para a abertura. As entrevistas com a Secretaria de Turismo, de um lado, e com pessoas ligadas ao trade turístico de outro, mostram tal impasse. Por fim, o artigo finaliza apontando que, na medida do possível, Pernambuco tem realizado um enfrentamento positivo à crise, inclusive, no que tange ao setor de turismo, buscando dar alternativas dentro do cenário apresentado.

Palavras-chave: Turismo. Políticas públicas. Pernambuco. Pandemia. COVID-19.

\section{ABSTRACT}

The aim of this article is to evaluate how the State of Pernambuco, Brazil, through its public policies, has responded to the COVID-19 pandemic concerning the tourism sector. Therefore, the study presents an overview of the impacts caused by the pandemic, considering the first semester of 2020, on public accounts, air traffic, accommodation and employability, based on transparency websites and other open information provided by federal and state governments. The creation of the Northeast Scientific Committee and its recommendations on pandemic response are analysed in order to establish the adoption (or not) of such guidelines for the achievement of state decrees aimed at combating the pandemic. It is intended to highlight how the state of Pernambuco seeks to manage the crisis by weighing both sides of the scale: The Consortium's recommendations and sector's pressure to reopen through the interviews with the Secretariat of Tourism, on the one hand, and with people linked to the tourist trade on the other, reveal such impasse. Lastly, the article concludes by pointing out that, as far as possible, Pernambuco has faced the crisis positively, including welcoming the tourism sector, making efforts to provide alternatives within the presented scenario.

Keywords: Tourism. Public Policy. Pernambuco. Pandemic. COVID-19.

\section{RESUMEN}

Este artículo pretende evaluar cómo el Estado de Pernambuco, a través de sus políticas públicas, ha enfrentado la pandemia del COVID-19 en relación con el sector turístico. Para ello, se presenta un panorama del impacto de la pandemia, considerando el primer semestre de 2020 , en las cuentas públicas, la circulación aérea, el alojamiento y el empleo, utilizando como fuente de datos los canales de transparencia y otras informaciones públicas emitidas por los gobiernos federal y estatal. Se comparan la creación del Comité Científico del Nordeste y sus recomendaciones para el combate de la pandemia con el fin de establecer la

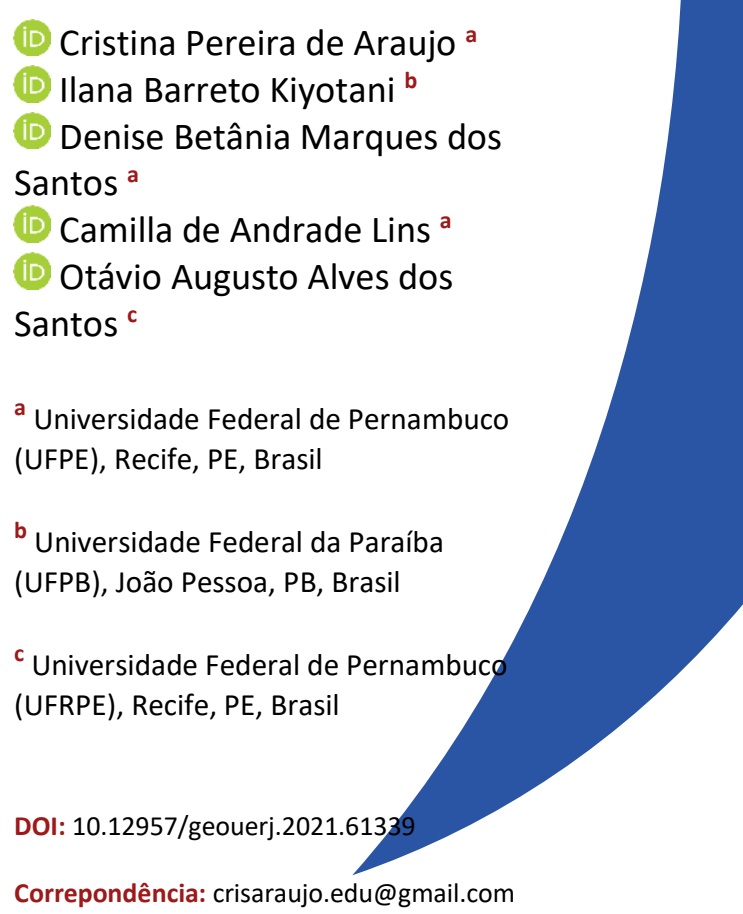

Recebido em: 14 mar. 2021

Aceito em: 1 jul.2021 
adopción (o no) de dichas directrices para la elaboración de decretos estatales dirigidos a combatir la epidemia. Se pretende destacar cómo el estado de Pernambuco busca gestionar la crisis equilibrando los dos lados de la balanza: las recomendaciones del Consorcio y la presión del sector por la apertura. Las entrevistas con el Secretario de Turismo, por un lado, y con personas vinculadas al comercio turístico, por otro, muestran ese impase. Para finalizar, el artículo señala que, en la medida de lo posible, Pernambuco ha afrontado la crisis de forma positiva, incluso acogiendo al sector turístico, tratando de ofrecer alternativas dentro del escenario planteado.

Palabras-clave: Turismo. Políticas públicas. Pernambuco. Pandemia. COVID-19. 


\section{INTRODUÇÃO}

25 de fevereiro de 2020. Polo do Marco Zero, principal polo do Carnaval do Recife. Maestro Spok e orquestra encarregam-se da festa de encerramento de mais um Carnaval na cidade do Recife que recebeu um público de 2 milhões de pessoas durante a festa de Momo (OLIVEIRA, 2020). Um número recorde, segundo a Prefeitura do Recife: 400 mil brincantes a mais que em 2019 (OLIVEIRA, 2020).

Quarta-Feira de Cinzas. 26 de fevereiro de 2020. O Bacalhau do Batata encerra mais um carnaval exitoso nas ladeiras de Olinda. Segundo dados da Prefeitura de Olinda, durante os sete dias de festa, foram movimentados $\mathrm{R} \$ 295$ milhões na cidade, que recebeu 3,6 milhões de brincantes, dentre eles, 400 mil turistas estrangeiros (VERISSIMO, 2020). Foram 100 mil estrangeiros a mais que em 2019 e um faturamento de R\$ 5 milhões, superior ao do ano anterior.

O Aeroporto Internacional do Recife registrou um fluxo de 226 mil passageiros entre os dias 17 e 25 de fevereiro de 2020, registrando 100 voos extras. Segundo dados da Associação Brasileira da Indústria de Hotéis (ABIH), a ocupação hoteleira foi na ordem de $98 \%$ (VERISSIMO, 2020).

Segundo o Portal da Cultura Pernambucana (CULTURA.PE, 2020), o Governo de Pernambuco, por meio da Secretaria da Cultura/Fundarpe e da Setur/Empetur, apoiou a realização do carnaval em 65 municípios distribuídos na Região Metropolitana do Recife, Zona da Mata, Agreste e Sertão, marcando a interiorização do carnaval pernambucano, somando investimentos na ordem de $\mathrm{R} \$ 10$ milhões.

Estado, municípios e iniciativa privada, notadamente o setor de hotéis e restaurantes, comemoravam o que teria sido o melhor Carnaval dos últimos tempos e já se preparavam para o Carnaval de 2021 - só não esperavam que a pandemia da COVID-19, um novo tipo de Coronavírus, eclodiria nesse meio tempo.

Em 14 de março de 2020, domingo, todas as Universidades e Institutos Federais, além da Universidade Estadual e da Universidade Católica (ambas integrantes do Consórcio Universitas), interrompem as aulas presenciais, num comunicado conjunto entre Estado, Prefeitura e Reitores. No sábado, 14 de março, um decreto estadual publicado no Diário Oficial paralisa o funcionamento de todas as escolas públicas e privadas a partir de 18 de março (Decreto $\mathrm{n}$-48.809). Em 01 de abril de 2020, numa tentativa intempestiva de gerar informação confiável em detrimento ao descaso do Governo Federal, os nove Estados do Nordeste unem-se em torno do Comitê Científico do Consórcio Nordeste para a COVID-19, que passa a divulgar, em sua página eletrônica, recomendações para orientar as ações dos Estados e Municípios no combate à pandemia. Pernambuco para. A economia para. O setor de turismo sofre com a pandemia. Certamente, o vírus já circulava no Estado durante o Carnaval. 
É nesse cenário de pós-carnaval e de um ano que não acabou que o presente artigo tem como objetivo avaliar como o Estado de Pernambuco tem enfrentado a pandemia, por meio da consecução de políticas públicas, tomando como recorte o setor de turismo, visando minimizar o seu impacto.

Para tanto, além desta introdução, o artigo traz mais quatro partes. A primeira trata do impacto direto da COVID-19 no setor de empregos das atividades relacionadas ao setor de turismo, assim estabelecidas pelo Cadastro Nacional de Atividades de Emprego (CNAE), na arrecadação, no fluxo aéreo e no setor de hospedagem, tendo como fonte de coleta os dados disponibilizados pelos portais de transparência do Estado e da ABIH. A segunda parte trata da criação do Comitê Científico do Consórcio do Nordeste para a COVID-19 e suas recomendações para a contenção de vírus no âmbito estadual. A terceira parte traz o impasse enfrentado pelo Estado de Pernambuco, tendo, de um lado, as recomendações do Consórcio que reverteram em uma série de decretos na tentativa de conter o espraiamento do vírus e, de outro, a pressão da economia, com ênfase ao setor turístico, lutando para sobreviver num cenário inóspito aos encontros e às viagens. Esse tópico traz uma compilação das políticas públicas empreendidas pelo Governo Estadual relacionadas ao setor de turismo, e, a partir de entrevistas com os entes públicos e privados, avalia-se a percepção de tais políticas. Por fim, nas considerações finais, faz-se um balanço da resposta institucional à crise de COVID-19 e sua percepção pelo setor de turismo.

\section{Os impactos da pandemia da COVID-19}

Os impactos decorrentes da paralisação das atividades econômicas foram imediatos no Estado de Pernambuco, e o setor do turismo sofreu profundamente tais impactos. Consideram-se como atividades relacionadas a este setor todas aquelas definidas pelo CNAE, quais sejam: os setores de hospedagem, restaurantes, locação de automóveis, agência de viagens, operadores turísticos, serviços de reserva e atividades de organização de eventos.

A partir de informações disponibilizadas pelo Cadastro Geral de Empregados e Desempregados (CAGED), pode-se perceber que, no Recife, o balanço entre admissões e demissões no primeiro semestre foi negativo para todos esses setores. Destes, o mais afetado em números absolutos foi o de restaurantes, que apresentou um saldo negativo de 3.260 demissões, variação correspondente a $800 \%$, se comparado com o mesmo período de 2019. O setor de hotelaria, por sua vez, registrou saldo negativo de 972 perdas no primeiro semestre, o que representou variação negativa de 19.440\%, se comparado com o mesmo período de 2019 (MINISTÉRIO DA ECONOMIA, 2020).

Em Ipojuca, o mais importante destino turístico do Litoral Sul do Estado, onde se localizam praias famosas, como Porto de Galinhas e Muro Alto, o setor de hospedagem apresentou saldo negativo de 2.393 no 
primeiro semestre de 2020 , atingindo uma variação negativa na ordem de $24.000 \%$. Já o setor de restaurantes registrou saldo negativo de 247 postos.

O distrito de Fernando de Noronha, outro importante destino turístico do Estado, apresentou comportamento similar, registrando um saldo negativo de 69 postos de trabalho no setor de restaurantes e 130 no setor de hotelaria, apenas no primeiro semestre de 2020.

A despeito da recuperação ocorrida no segundo semestre de 2020, o Estado apresentou variação positiva de apenas 0,11 no acumulado do ano em todos os ramos da economia, o que não representou uma diminuição substancial da massa de trabalhadores desempregados (MINISTÉRIO DA ECONOMIA, 2020). Neste contexto, os setores relacionados ao turismo ainda não conseguiram se recuperar dos impactos da paralisação das atividades entre os meses de março e junho de 2020. O saldo do emprego no turismo entre março e setembro de 2020 foi de 108 mil empregos a menos (DOURADO, 2020).

Segundo o próprio CAGED (MINISTÉRIO DA ECONOMIA, 2020), no pior momento da epidemia, entre março e junho de 2020 , todo o País perdeu mais de 1,6 milhões de postos de trabalho, e, em que pese a recuperação e a sucessão de saldos positivos no segundo semestre, o ano fechou com saldo positivo muito pequeno, algo em torno de $0,9 \%$ no acumulado, o que não representa efetivamente um aumento da massa de trabalhadores empregados.

O setor do turismo, porém, está longe de qualquer recuperação efetiva. Estima-se que os setores relacionados recuaram 36,7\% em relação a 2019, segundo dados da Confederação Nacional de Comércio de Bens, Serviços e Turismo (CNC), com base na Pesquisa Mensal de Serviços do Instituto Brasileiro de Geografia e Estatística (PMS/IBGE). Em entrevista cedida ao portal de notícias UOL (OLIVEIRA, 2020), o presidente da Associação Brasileira das Operadoras de Turismo (BRAZTOA) afirmou que, em todo o ano de 2020, o faturamento do setor não chegou a 50\% do que foi obtido em 2019, e a recuperação total se dará apenas em 2023. Em Pernambuco, a perda apurada do setor do turismo foi da ordem de 7 bilhões de reais entre março de 2020 e janeiro de 2021 (OLIVEIRA, 2020).

A pandemia também afetou fortemente a arrecadação de impostos. Os dados comparativos entre os primeiros semestres de 2019 e 2020 revelam que a arrecadação do Imposto sobre Circulação de Mercadorias e Prestação de Serviços (ICMS) caiu substancialmente. A capital do Estado perdeu cerca de $15 \%$ na arrecadação, e municípios como Ipojuca perderam 50\%. Destaque também para o distrito de Fernando de Noronha, que teve redução de 40\%. Para o ISS (Imposto Sobre Serviços), cuja arrecadação é municipal, observou-se que as perdas foram na ordem de $10 \%$ para os três principais destinos turísticos do Estado (Recife, Ipojuca e Fernando de Noronha). O Recife foi um dos mais afetados, apresentando queda de mais de 900 
milhões de reais na arrecadação municipal (JATOBÁ, 2020). Também houve redução de $10 \%$ na arrecadação dos impostos federais no Estado.

Isso, naturalmente, impactou as finanças públicas. A arrecadação no Estado de Pernambuco durante o ano de 2020 foi equivalente a 36,8 bilhões de reais, o que representou aproximadamente $88 \%$ do que estava previsto pela Lei Orçamentária Anual.

As desonerações implementadas no contexto de enfrentamento dos impactos econômicos da pandemia consistiram no fator que mais contribuiu com essa queda. Mas parte dela foi amenizada pelas ajudas federais enviadas durante o ano e pelo auxílio emergencial, que foi gasto em consumo para as famílias, convertendose em arrecadação para o Estado. Segundo o Secretário da Fazenda de Pernambuco, Décio Padilha, o auxílio emergencial injetou mais de 10 bilhões de reais no Estado (RÁDIO JORNAL, 2020).

Mas uma das melhores formas de conhecer a dimensão do impacto da pandemia no turismo é por meio dos fluxos de voos. Sabe-se que o número de voos que aportam a uma determinada localidade tem relação direta com a entrada de turistas, de modo que o aumento ou a redução deles quase sempre interfere na dinâmica de todo o setor.

A parte mais representativa dos fluxos turísticos para o Estado de Pernambuco chega a partir de dois aeroportos: o Internacional do Recife/Guararapes - Gilberto Freyre, no Recife, e o Aeroporto de Fernando de Noronha - Governador Carlos Wilson, no arquipélago de Fernando de Noronha. Considerando-se o início das medidas de isolamento social (março) até o mês de junho, a diminuição dos voos comerciais nacionais e internacionais para esses dois aeroportos foi $50 \%$ em média, em comparação com o mesmo período do ano anterior. Ambos tiveram uma redução nos números de voos de chegada na ordem de $90 \%$ nos meses de abril e maio (MINISTÉRIO DA INFRAESTRUTURA, 2020).

O Aeroporto Internacional do Recife/Guararapes - Gilberto Freyre recebeu cerca de 2.871 voos nacionais e 123 voos internacionais no mês de março de 2019. No mês em que foram estabelecidas as primeiras restrições, em março de 2020, este aeroporto ainda recebeu 2.087 voos nacionais e 75 internacionais, o que representou uma diminuição de apenas $27 \%$ dos nacionais e $40 \%$ dos internacionais. Mas o mês de abril, na comparação com o ano anterior, teve a importante queda de $90 \%$ para voos nacionais e $89 \%$ para voos internacionais. Em maio, a queda foi de $88 \%$ para os nacionais e $91 \%$ para os internacionais. E, ainda na comparação com o ano anterior, junho teve diminuição de $79 \%$ para nacionais e $86,5 \%$ para internacionais. No acumulado do primeiro semestre de 2020, o Aeroporto Internacional do Recife/Guararapes - Gilberto Freyre recebeu 9.523 voos nacionais e 366 voos internacionais, 7.140 e 350 (respectivamente) a menos que em 2019. Isto significou uma queda de $43 \%$ em voos nacionais e $49 \%$ em voos internacionais (MINISTÉRIO DA INFRAESTRUTURA, 2020). 
O aeroporto de Fernando de Noronha - Governador Carlos Wilson esteve fechado entre os meses de março e agosto de 2020 por força de decreto estadual. Com efeito, no mês de março de 2020, o supracitado aeroporto teve $29 \%$ de redução da chegada de voos (nacionais). Em abril de 2019, chegaram ao arquipélago cerca de 140 voos, mas, em 2020, foram apenas 6, o que representou uma queda de $96 \%$. Ainda no comparativo com o ano anterior, maio de 2020 teve queda de $97,3 \%$ da chegada de voos, e junho, $94 \%$. No acumulado do primeiro semestre de 2020 , chegaram apenas 436 voos ao arquipélago, número $51 \%$ menor que o de 2019, que havia sido de 887 (MINISTÉRIO DA INFRAESTRUTURA, 2020).

Ainda no tocante aos fluxos aeroportuários, o número de passageiros domésticos desembarcados durante o primeiro semestre de 2020 no Recife foi de 1.085 .860 passageiros, muito abaixo dos 1.963 .086 desembarcados em 2019. Já em Fernando de Noronha, variou de 70.754, em 2019, para 34.875, em 2020. Em outras palavras, no comparativo entre os primeiros semestres de 2019 e 2020, houve uma redução de $45 \%$ no Recife e 51\% em Fernando de Noronha. Quanto aos passageiros internacionais desembarcados no primeiro semestre de 2019 e de 2020, houve uma redução de 118.878 para 54.018 no Recife, o que representou uma queda de 55\% (MINISTÉRIO DA INFRAESTRUTURA, 2020).

A redução nos fluxos e a baixa entrada de turistas impactaram negativamente nos serviços turísticos. Estima-se que Pernambuco tenha perdido aproximadamente 1,2 mil empresas ligadas à atividade (DOURADO, 2020). Dentre esses setores, o mais afetado foi o de hospedagem. Segundo Rodrigo Novaes, Secretário de Turismo de Pernambuco, entre maio e junho de 2020, 90\% dos hotéis do Estado estavam fechados, e os 10\% em funcionamento estavam apenas com 5\% da ocupação (MOROSINI, 2020).

De março a setembro de 2020, a atividade hoteleira de Fernando Noronha teve suas atividades suspensas por 165 dias; Ipojuca, por 96 dias, e o Recife não chegou a suspender as atividades, mas teve redução de mais de $50 \%$ da taxa de ocupação durante o período. Na capital, a taxa de ocupação hoteleira caiu de $65 \%$, no primeiro semestre de 2019 , para $34 \%$, no primeiro semestre de 2020 . E as expectativas eram as piores diante da não realização do Carnaval de 2021 (MEIRELES, 2021), uma vez que é precisamente durante a festa de Momo que o Estado recebe a maior quantidade de turistas durante o ano.

Os números demonstram como a atividade turística (notadamente o setor hoteleiro e restaurantes) foi impactada com a pandemia. O número de demissões é alarmante, os voos diminuíram pela metade, e se, de um lado, os empresários ficaram sem giro de capital para manter seus negócios, resultando em fechamento de empresas, por outro, os trabalhadores do setor se viram, de uma hora para outra, sem emprego e tendo que buscar alternativas para manter sua subsistência, como, por exemplo, transformando-se em entregadores 
por meio de aplicativos e expondo-se a toda sorte de riscos, para além da COVID-19, em troca de uma remuneração aquém de seus esforços laborais ${ }^{1}$.

Ambos, empregadores e empregados voltaram-se para o Estado em busca de auxílio. O Estado, por sua vez, tem no Consórcio Nordeste um balizador importante para a tomada de decisões. Pretende-se demonstrar, nas duas próximas seções, como o Estado tem lidado de sorte a mitigar a pandemia, ouvindo, de um lado, o Consórcio Nordeste e sentindo, de outro, a pressão do setor.

\section{O olhar científico sobre a crise: as recomendações empreendidas pelo Consórcio Nordeste}

As intervenções do Estado na dinâmica da sociedade se dão primordialmente por meio de políticas públicas. Algumas são desenvolvidas ou ampliadas ancoradas na redação constitucional, portanto, contínuas; outras são transitórias e reflexo de cada gestão. Para Souza (2006), essa temática coloca em tela um campo de debates e tensão, no qual o governo é o protagonista a partir da formulação de conceitos e teorias advindos da área da ciência política, cujos processos são complexos e envolvem relações em vários níveis e diversidade de sujeitos (ARAÚJO, RODRIGUES, 2017). Políticas públicas devem ser garantidoras de direitos humanos para as quais precisa prevalecer o respeito fundamental ao direito à vida.

Contudo, no que tange às políticas públicas norteadoras da atividade turística no Brasil, estas mostraram-se tímidas em alguns casos e, em outros, inacessíveis, em face da pandemia provocada pela COVID19. As crises, sejam elas econômicas ou sanitárias, exigem uma resposta coordenada e rápida por parte do poder público. Situações de calamidade requerem dos governantes urgência e compromisso com o bem-estar geral, a fim de se promover proteção e amparo para a população (KIND, CORDEIRO, 2020).

No caso da COVID-19, foram os Estados brasileiros os protagonistas das medidas sociais, econômicas e sanitárias mais incisivas, no intuito de conter as consequências da pandemia, não se assemelhando em nada à postura praticamente inerte (para não dizer negacionista) do Governo Federal. Porém, as medidas tomadas mostraram-se relativamente lentas e pouco eficientes, frente ao inesperado infortúnio do vírus SARS-CoV-2, sobretudo, no início do contágio, apesar da era informacional ter sido capaz de, em tempo real, mostrar a migração e proliferação da COVID-19 nos diversos países, alertando aos demais para o caos geral que se instaurava.

A pandemia expôs diversas fragilidades do território nacional. As desigualdades sociais ficaram mais evidentes, e a precarização do emprego formal (que já vinha sendo apontada desde 2016) tornou-se mais

\footnotetext{
${ }^{1}$ Em julho de 2020, os entregadores de aplicativos promoveram duas greves nacionais em busca de melhores condições de trabalho. (PEREIRA, 2020)
} 
profunda. A economia estagnou em alguns setores, a exemplo do turismo, contribuindo para o aumento da pobreza (ORTIZ, 2020). O atual desestímulo ao investimento em ciência e tecnologia nos diversos setores e a completa ausência na área de imunização são situações de fragilidade em que o país já se encontrava, consequência da Emenda Constitucional no 55 e da rígida disciplina fiscal, e que, somadas à pandemia, tornaram-se incontornáveis.

Nesse contexto, Silva e Muniz (2020) destacam o aprofundamento das problemáticas sociais, mormente, nos aglomerados urbanos, onde a complexa dinâmica do emprego informal e a debilidade da moradia são flagrantes. Já Kind e Cordeiro (2020) realçam o enorme desafio enfrentado pelos governos para dar proteção e cobertura por parte do sistema de saúde, asfixiado pelo corte de investimentos da já citada Emenda Constitucional no 55. A situação chega ao seu limite expressa pela falta de oxigênio nos hospitais do Estado do Amazonas, fato tão amplamente divulgado, tendo movimentado diversos cidadãos para a mitigação dessas questões (GORTÁZAR, 2021).

Diante desse cenário de cortes e ausência de Estado, é notável que os Estados do Nordeste do Brasil se destaquem como um bloco homogêneo, compartilhando desde problemas muito parecidos que requerem soluções igualmente semelhantes, até visões políticas, principalmente no atual contexto político nacional. Nesse sentido, historicamente, tem-se construído uma identidade regional marcada institucionalmente pela criação da Superintendência do Desenvolvimento do Nordeste (SUDENE) no fim da década de 1950, e, mais recentemente, pela necessidade de discussões acerca de pautas colocadas por esta autarquia, de modo que os chefes do executivo dessa região têm organizado o Fórum dos Governadores do Nordeste quase anualmente desde a década de 2000, estreitando ainda mais as relações entre os nove Estados.

Embora não fosse incumbência principal do Fórum, o posicionamento político, a turbulenta conjuntura desse campo no ano de 2015, com o aceite do pedido de impeachment da presidenta Dilma Rousseff pelo então presidente da Câmara dos Deputados, Eduardo Cunha, conduziu seus participantes a tornarem público, no dia seguinte, o repúdio a este ato por meio de uma carta (PORTAL G1, 2015). A partir de então, as divergências políticas entre os governos da região e o Governo Federal apenas se ampliaram, principalmente após a eleição do atual presidente, Jair Bolsonaro, em 2018.

Como explicam Rossi e Silva (2020), foi este panorama que culminou na criação, em março de 2019, do Consórcio Interestadual de Desenvolvimento Sustentável do Nordeste (Consórcio Nordeste), ratificado em julho do mesmo ano em reunião destes governadores, tendo como marco legal a Lei no 11.107/2005, que regulamenta os consórcios públicos no País.

O Consórcio Nordeste traz facilidades para negociações em conjunto para a região, além de fortalecer a união do bloco nos sentidos identitário e político (CLEMENTINO, 2019). A página online do consórcio explica 
que sua criação trouxe como possibilidades "a realização de compras conjuntas, a implementação integrada de políticas públicas e a busca por cooperação, também em nível internacional”2 . Clementino (2019) aponta que seus objetivos convergem com o Plano Regional de Desenvolvimento do Nordeste, lançado pela SUDENE em 2019, e que esta iniciativa de associação aponta a urgência de um projeto para a região, possibilidade que se distancia cada vez mais devido à falta de sintonia entre as esferas federal e estaduais e a descontinuidade de financiamentos a políticas públicas para o Nordeste.

Após a declaração da pandemia da COVID-19 em março de 2020, o Brasil se viu perdido quanto a quais medidas sanitárias e econômicas deveriam ser adotadas para minimizar toda a crise que estaria por vir, já que o Presidente da República se absteve de indicar caminhos pautados em pesquisas científicas para que Estados e municípios pudessem seguir. Diante disto, a solução vista pelos governos dos Estados nordestinos foi a atuação por meio do Consórcio Nordeste, principalmente no tocante à compra de materiais e insumos necessários ao enfrentamento da nova doença, contando, inclusive, com a articulação direta do Consórcio com outros países ${ }^{3}$.

Foi, então, instaurado o Comitê Científico de Combate ao Coronavírus do Consórcio Nordeste (C4NE) em abril de 2020, no qual especialistas trazem recomendações para orientar os governos estaduais e municipais pautados em pesquisas científicas e projetam cenários mediante o acompanhamento da trajetória do vírus e da pandemia como um todo. Fazem parte do C4NE além de pesquisadores das áreas envolvidas, representantes dos estados-membros do Consórcio Nordeste, sendo também assessorados por profissionais de renome internacional (C4NE, 2020). O C4NE possui nove subcomitês temáticos com o objetivo de agrupar os diferentes campos do conhecimento e agregar profissionais voluntários específicos de cada área.

Até março de 2021, foram emitidos catorze boletins desde o início dos trabalhos do C4NE. Algumas recomendações impactam direta ou indiretamente a atividade turística nos municípios e Estados. Em 01 de abril de 2020, o Boletim $01^{4}$ apontou que medidas restritivas legais deveriam ser decretadas pelos governos

\footnotetext{
${ }^{2}$ A página também anuncia como objetivos do consórcio "promover a integração regional; articular e implementar políticas públicas integradas; ampliar e modernizar a infraestrutura de exploração dos recursos naturais da região; atrair investimentos internos e externos para região Nordeste; modernizar a gestão dos Estados Membros e buscar parcerias com o setor privado; realizar compras compartilhadas; promover o desenvolvimento sustentável, respeitando o meio ambiente e a democracia; fortalecer a participação de micro e pequenas empresas na economia regional; gerar o bem-estar social na região". Disponível em: <http://www.consorcionordeste-ne.com.br/o-consorcio/>. Acesso em: 19 fev. 2021.

${ }^{3}$ Tais iniciativas para articulações internacionais já vinham ocorrendo no âmbito do Consórcio no fim de 2019, quando seus representantes estiveram na França, Alemanha e Itália em busca de potenciais investidores para a região. Disponível em: <http://www.consorcionordeste-ne.com.br/o-consorcio/>. Acesso em: 19 fev. 2021.

${ }^{4}$ Os boletins foram publicados nas seguintes datas: 01, 01/04/2020; 02, 03/04/2020; 03, 09/04/2020; 04, 16/04/2020; 05, 24/04/2020; 06, 05/05/2020; 07, 21/05/2020; 08, 01/06/2020; 09, 02/07/2020;10, 11/08/2020; 11, 17/09/2020; 12, 02/10/2020; 13, não disponibilizado no sítio eletrônico; 14, 12/02/2021. Disponível em: < https://www.comitecientificone.com.br/c4ne/boletins>. Acesso em: 20 fev. 2021.
} 
com vistas ao isolamento e ao distanciamento social, para interromper ou diminuir ao máximo o contágio do novo Coronavírus e evitar, assim, a sobrecarga das redes pública e privada de saúde, com uma grande quantidade de pessoas infectadas e necessitando de cuidados hospitalares ao mesmo tempo.

Deste modo, as atividades não essenciais e de lazer, que normalmente estão atreladas ao turismo, foram as primeiras recomendadas pelo referido boletim ao fechamento: eventos de qualquer natureza; vendas presenciais (de artigos não essenciais); atividades religiosas; atividades de lazer em praças, parques e praias; funcionamento de bares e restaurantes. Acrescido a isto, aconselhou-se a implantação de testagem em aeroportos e rodoviárias, o que não ocorreu em Estados nordestinos nem em outras regiões.

No Boletim 04, de 16/04/2020, os especialistas recomendaram a proibição das viagens intermunicipais e interestaduais pelo Nordeste, tendo em vista o crescente número de contágio pelo novo Coronavírus na região e no Brasil. Vários Estados brasileiros passaram a aplicar medidas de segurança sanitária nas estradas e rodovias, mas, em Pernambuco, não houve fechamento de divisas nem aplicação de testes em motoristas e passageiros; apenas foram suspensas as viagens intermunicipais e interestaduais por transporte coletivo rodoviário (GARCIA, PASSOS, TOLEDO et al, 2020), antes mesmo da recomendação do Comitê.

Dentre outras recomendações do Comitê que afetaram principalmente as atividades turísticas da região Nordeste e, consequentemente, o Estado de Pernambuco, estão a proposta de lockdown para os Estados que chegassem a $80 \%$ de ocupação dos leitos hospitalares com curvas de casos e óbitos crescentes, presente no Boletim 06, de 05/05/2020, e um apelo para a continuidade do lockdown no Boletim 07, de 21/05/2020, quando, em Pernambuco, isto já era posto em prática na região metropolitana 5 .

O não fechamento da malha rodoviária no Estado facilitou o espraiamento da COVID-19 para municípios do interior, como Petrolina, Serra Talhada e Caruaru, estes apresentando altas curvas de contágio, como relatado no Boletim 09, de 02/07/2020. Os Boletins 10, 11 e 12 apontaram para uma estabilização da pandemia em Pernambuco em risco moderado durante os meses de setembro e outubro. O Boletim 14, de 12 de fevereiro de 2021, apresenta um alerta para altos riscos pandêmico e epidêmico em Pernambuco, com a projeção do aumento de óbitos e novos casos da doença baseados nos dados estatísticos reais.

Em fevereiro de 2021, a saída do neurocientista Miguel Nicolelis (BERGAMO, 2021), que coordenava o C4NE junto com o físico Sérgio Rezende, demonstra a insatisfação dos cientistas quanto ao comportamento dos governadores integrantes do Consórcio Nordeste, que passaram a não seguir as últimas recomendações do Comitê para o aumento do isolamento social, a restrição de circulação de pessoas e até a necessidade de

\footnotetext{
${ }^{5}$ A capital Recife e mais quatro municípios da região metropolitana entraram em lockdown no período de 16 a 31 de maio de 2020.
} 
um novo lockdown. No início de janeiro de 2021, Nicolelis alertou para o crescimento alarmante de novas contaminações da COVID-19 no Brasil, demandando que todo o País entrasse em lockdown, assim como países da Europa estavam fazendo, incluindo também o fechamento de aeroportos internacionais, a exemplo de outros países sul-americanos (PORTAL G1, 2021). O cientista também deixou clara a urgência de uma coordenação nacional contra a pandemia, mas nenhuma de suas recomendações foi posta em prática até então.

A ação do Governo e a reação do trade na pandemia: entre a ciência e a economia

Embasado pelas recomendações do Comitê, o Governo do Estado de Pernambuco promulgou uma série de decretos na tentativa de conter o avanço da pandemia e que impactaram diretamente o setor de turismo e sua cadeia produtiva. Como forma de mitigar o impacto na atividade, o Estado promoveu 30 medidas, das quais quatro dizem respeito à esfera social, outras quatro, ao âmbito econômico, e vinte e dois à questão sanitária (elencadas no Quadro 1). As medidas sociais preocuparam-se prioritariamente em dar estabilidade à categoria de guias de turismo, promovendo a distribuição de aproximadamente 1.110 cestas básicas.

Também inédita foi a criação do balcão de informações turísticas, por meio da rede social WhatsApp, para que os empresários e profissionais do trade pudessem consultar e receber informações acerca da legislação trabalhista, já que inúmeros estabelecimentos precisaram suspender suas operações e/ou reduzir o quadro de colaboradores. Também foram divulgadas informações sobre acesso ao crédito turístico oferecido pelas agências multilaterais.

Duas das medidas sociais foram adaptadas de ações já existentes, como a oferta de cursos de qualificação online e gratuitos, em uma parceria da Secretaria de Turismo e Lazer com a Secretaria do Trabalho, Emprego e Qualificação e o Instituto Federal de Pernambuco (IFPE), com vistas à formação de agentes de informações turísticas.

Já as medidas econômicas concentraram-se marcadamente no apoio ao núcleo produtivo do artesanato, visto que duas das quatro medidas se dirigem ao auxílio direto ou indireto a essa categoria, seja na compra de peças artesanais, por parte da Agência de Desenvolvimento Econômico de Pernambuco (AD Diper), seja pelo estímulo à aquisição do artesanato, por parte de quaisquer demandas, por meio de redes sociais exclusivas.

Em oferta menos específica, mediante o Decreto 48.875, de 31 de março de 2021, que beneficiou as empresas de modo geral e, consequentemente, do setor de turismo, foi concedida a prorrogação de prazos relativos ao pagamento das obrigações tributárias acessórias. Por último, foi criada uma linha de crédito específica para os guias de turismo. 
Observa-se que há, por parte do governo pernambucano, uma preocupação específica com as atividades em que a informalidade se apresenta com maior incidência. Essa condição dentro da atividade turística é recorrente e marcante entre guias de turismo e artesãos, o que, em certa medida, explica a prevalência dada às políticas de suavização aos danos sociais e econômicos da pandemia, com foco nestas categorias.

As medidas protetivas de atenção sanitária predominaram na legislação pernambucana. Foram 17 decretos e uma ação sem legislação correspondente, mas que trata de dar prosseguimento à implementação dos protocolos indicados pelo Governo Federal, que abordam o Selo Turismo Seguro. Assim, 12 protocolos contemplam os segmentos de (i) agências de viagens e operadoras; (ii) atrativos turísticos; (iii) bares e restaurantes; (iv) centros de convenções; (v) eventos; (vi) guias de turismo; (vii) locadoras de veículos; (viii) meios de hospedagem; (ix) parques aquáticos; $(x)$ parques temáticos; (xi) transportadoras turísticas e (xii) turismo náutico, todos criados para orientar a retomada, no que se convencionou denominar de "novo normal".

As leis e os decretos sanitários criados, conforme é possível identificar no Quadro 1, regulamentam o funcionamento de diversos segmentos, deliberando sobre permissões, restrições, como também suspensões. A atenção se volta, primordialmente, para impedir que aglomerações possam se formar e o turismo venha a ser atividade vetor de contaminações, já que é responsável pela mobilidade de milhões de pessoas e objetos em escala internacional. Trata-se de uma das primeiras atividades a ser impactada pela pandemia e, certamente, será uma das últimas a retomar plenamente, dando-se o maior prejuízo nos empreendimentos locais, cujo capital poderá levar anos para se restabelecer.

Nesse quadro, importa destacar as leis ordinárias, aprovadas em 2021, de caráter social e protetivo que visam implantar o ciclo carnavalesco, de apoio financeiro a artistas e a grupos culturais pernambucanos, bem como o apoio aos artesãos.

Quadro 1. Leis e decretos sanitários emitidos pelo Governo de Pernambuco durante a pandemia. Fonte: elaborado pelos autores (2021)

\begin{tabular}{|c|c|c|}
\hline Decretos Estaduais & Conteúdo & Status (até 28.02.2021) \\
\hline № 50.077 de 21.01 .2021 & \multirow{7}{*}{$\begin{array}{l}\text { Tratam da autorização/suspensão de eventos de qualquer } \\
\text { natureza, seja institucional, corporativo ou público, shows, } \\
\text { festas e similares, inclusive carnaval. }\end{array}$} & \multirow{7}{*}{$\begin{array}{l}\text { Liberado com restrição no } \\
\text { número de participantes }\end{array}$} \\
\hline № 50.052 de 07.01.2021 & & \\
\hline № 49.891 de 07.12 .2020 & & \\
\hline № 49.668 de 30.10 .2020 & & \\
\hline № 49.563 de 13.10 .2020 & & \\
\hline № 48.837 de 23.03 .2020 & & \\
\hline № 48.822 de 17.03 .2020 & & \\
\hline $\begin{array}{c}\text { № } 48.830 \text { de } \\
18.03 .2020\end{array}$ & $\begin{array}{l}\text { Suspensão de desembarque e circulação de tripulação de } \\
\text { navios, no âmbito do Porto }\end{array}$ & Liberado \\
\hline $\begin{array}{c}\text { № } 50.258 \mathrm{de} \\
10.02 .2021\end{array}$ & & $\begin{array}{l}\text { A proibição foi restrita aos } \\
\text { horários das } 20 \mathrm{~h} \text { às } 5 \mathrm{~h}, \text { no }\end{array}$ \\
\hline
\end{tabular}




\begin{tabular}{|c|c|c|}
\hline № 49.250 de 31.07 .2020 & \multirow[b]{2}{*}{$\begin{array}{l}\text { Proibição da utilização de som em bares, lanchonetes, } \\
\text { restaurantes, similares e na faixa de areia das praias, até } \\
15.03 .2021 . \\
\text { Entre } 12 \text { e 15.02.21 proibição de funcionamento de bares, } \\
\text { lanchonetes, restaurantes e similares no Recife Antigo e Sítio } \\
\text { Histórico de Olinda; } \\
\text { Autoriza/suspende/permanece o funcionamento bares, } \\
\text { restaurantes e similares. }\end{array}$} & \multirow{2}{*}{$\begin{array}{c}\text { decorrer da semana e das } \\
17 \mathrm{~h} \text { às } 5 \mathrm{~h} \text { nos finais de } \\
\text { semana, de } 27.02 \text {.a } 10.03 .21\end{array}$} \\
\hline № 48.832 de 19.03 .2020 & & \\
\hline № 48.832 de 19.03 .2020 & $\begin{array}{l}\text { Interdição do acesso às praias e ao calçadão das avenidas } \\
\text { situadas nas faixas de beira-mar e de beira-rio e aos parques. }\end{array}$ & $\begin{array}{c}\text { Liberado ao público, } \\
\text { obedecendo às medidas de } \\
\text { proteção sanitária }\end{array}$ \\
\hline № 48.834 de 20.03 .2020 & Suspensão do funcionamento dos meios de hospedagem. & $\begin{array}{l}\text { Liberado ao público, } \\
\text { obedecendo às medidas de } \\
\text { proteção sanitária }\end{array}$ \\
\hline $\begin{array}{c}\text { № } 50.052 \text { de } \\
07.01 .2021 \\
\end{array}$ & \multirow{6}{*}{$\begin{array}{l}\text { Autoriza/suspende/permanece o funcionamento dos centros } \\
\text { de artesanatos, museus e demais equipamentos culturais. } \\
\text { Além das atividades culturais de cinema, teatro e demais } \\
\text { eventos culturais. }\end{array}$} & \multirow{6}{*}{$\begin{array}{l}\text { Liberado ao público, } \\
\text { obedecendo às medidas de } \\
\text { proteção sanitária }\end{array}$} \\
\hline № 49.668 de 30.10 .2020 & & \\
\hline № 49.542 de 09.10.2020 & & \\
\hline № 49.518 de 02.10 .2020 & & \\
\hline № 49.466 de 18.09 .2020 & & \\
\hline № 49.390 de 28.08 .2020 & & \\
\hline $\begin{array}{c}\text { № } 49.390 \mathrm{de} \\
28.08 .2020\end{array}$ & $\begin{array}{l}\text { Autorização para pousos e decolagens no aeroporto de } \\
\text { Fernando de Noronha. }\end{array}$ & $\begin{array}{c}\text { Permanece liberado, } \\
\text { obedecendo às medidas de } \\
\text { proteção sanitária }\end{array}$ \\
\hline Lei Ordinária & Descrição & Status \\
\hline $\begin{array}{c}\text { № } \begin{array}{c}17.163 \\
\text { de }\end{array} \\
11.01 .2021\end{array}$ & $\begin{array}{l}\text { Quando houver a oferta de vagas nas ações a que se refere o } \\
\text { artigo anterior, bem como nas demais ações relacionadas com } \\
\text { esta Lei, será reservado o percentual mínimo de } 30 \% \text { (trinta } \\
\text { por cento) para mulheres artesãs individuais ou entidades } \\
\text { representativas de mulheres artesãs. } \\
\text { Prestar apoio estratégico e permanente aos artesãos, } \\
\text { especialmente mediante promoção de qualificação } \\
\text { profissional. } \\
\text { Apoiar e acolher o artesão pernambucano durante e após } \\
\text { períodos caracterizados como calamidade pública, que } \\
\text { resultem em prejuízo à atividade e à cadeia produtiva do } \\
\text { artesanato no Estado de Pernambuco. } \\
\text { Promover a valorização e o empoderamento da mulher artesã, } \\
\text { estimulando o empreendedorismo feminino dentro da cadeia } \\
\text { produtiva do artesanato pernambucano. }\end{array}$ & Mantido \\
\hline $\begin{array}{c}\text { № } \begin{array}{c}17.165 \\
\text { de }\end{array} \\
26.02 .2021\end{array}$ & $\begin{array}{l}\text { Fica instituído o Auxílio emergencial “Ciclo Carnavalesco de } \\
\text { Pernambuco", destinado à concessão de auxílio financeiro a } \\
\text { artistas e a grupos culturais da tradição carnavalesca } \\
\text { pernambucana, que atuam no ciclo carnavalesco do Estado, } \\
\text { diante da impossibilidade de realização de eventos } \\
\text { carnavalescos por força das medidas restritivas adotadas em } \\
\text { decorrência da permanência da pandemia de COVID-19. }\end{array}$ & Mantido \\
\hline
\end{tabular}

De uma forma geral, a análise das leis e dos decretos emitidos permite inferir que houve uma ação incisiva do Governo Estadual no sentido de conter o avanço da pandemia, atendendo, até certo ponto, às 
recomendações empreendidas pelo Comitê Científico, pelo menos durante o ano de 2020, trazendo um foco social importante, para além do auxílio emergencial conferido pelo Governo Federal à população mais vulnerável.

No que tange a posicionamentos e a políticas de turismo visando à reabertura do setor, a Secretaria Estadual de Turismo (SETUR/PE) e a Empresa Pernambucana de Turismo (EMPETUR), em parceria com o trade, mobilizaram-se durante a pandemia para estabelecer os protocolos de segurança cabíveis para cada segmento.

A SETUR/PE, segundo entrevista concedida ${ }^{6}$, manteve-se atuante durante a interrupção do fluxo turístico, oferecendo cursos e oficinas para possibilitar o aperfeiçoamento da mão de obra e a melhoria na prestação de serviço em parcerias com o Serviço Brasileiro de Apoio às Micro e Pequenas Empresas (SEBRAE). Também manteve reuniões virtuais com ao menos 50\% dos municípios e criou o programa "Bora Pernambucar em Casa", buscando promover e incentivar o consumo da gastronomia local. Lançou promoções de destinos, incluindo a concepção do "Passaporte Pernambuco", uma iniciativa que estimula o acúmulo de vivências no Estado. Além disso, não deixou de planejar e organizar a promoção de novos destinos turísticos estaduais.

No entanto, tais ações parecem não ter sido suficientes para mitigar o impacto da pandemia. Segundo o representante da $\mathrm{ABIH} / \mathrm{PE}^{7}$, em entrevista: "o impacto [da pandemia] é devastador para o setor de hospedagem de Pernambuco e do Brasil. Sua retomada está sendo muito lenta, e sem definições claras de como vai ser um horizonte a médio e curto prazos".

Muitos foram os postos de trabalhos perdidos, entre falências e fechamentos de empresas do setor de turismo, eventos e alimentação. Os entraves trazidos pela pandemia levaram empresários, e sobretudo trabalhadores, à situação crítica de dívidas, perdas e difíceis condições de sustento. No setor hoteleiro, apesar de a $A B I H / P^{8}$ desconhecer casos de falência entre seus associados, a associação expôs que, no Recife, houve uma redução de 60 a 70\% da mão de obra na hotelaria durante o ano de 2020 .

Já o setor de alimentação fora do lar (AFL) destaca-se como o principal atingido pela pandemia (NOVAIS, 2020), tendo fechado muitos dos seus estabelecimentos e demitido grande número de funcionários (SEBRAE, 2020; ANR, 2020).

\footnotetext{
${ }^{6}$ Entrevista concedida em novembro de 2020.

${ }^{7}$ Entrevista concedida no mês de novembro de 2020.

${ }^{8}$ Idem.
} 
O representante da Associação Brasileira de Bares e Restaurantes (ABRASEL/PE) ${ }^{9}$ define a pandemia como "uma catástrofe" e alega que, em Pernambuco, 30\% do setor AFL não retornou após a reabertura dos bares e restaurantes, fecharam por falência ou falta de recursos:

Como temos 17.300 bares e restaurantes em todo o estado, cerca de 5.000 estabelecimentos encerraram suas atividades durante a pandemia ou não conseguiram reabrir após a liberação de funcionamento na reabertura. O número de desempregados no setor chegou a cerca de 12 mil, tendo Pernambuco ficado acima da média nacional.

Claramente, a preocupação é cabível para o trade turístico, que vê desde seus trabalhadores a seus empresários batalhando para se sustentar no mercado em meio ao caos que tomou conta do setor. Do lado empresarial, majoritariamente, alega-se que apenas as políticas públicas federais de linha de crédito e Medida Provisória 936 puderam colaborar para a manutenção dos empreendimentos ${ }^{10}$. Mais difícil ainda ficou a situação dos trabalhadores, no caso dos guias de turismo, que se viram sem qualquer turista para guiar e, assim, fomentar seu sustento. A única opção foi contar com o auxílio emergencial do Governo Federal e algumas poucas cestas básicas doadas pelo Governo Estadual e outras pelo Governo Municipal, no caso dos guias residentes no Recife.

Dentro deste contexto, as críticas ao setor público, no tangente à falta de políticas públicas mitigadoras do prejuízo, vêm da ABRASEL/PE e do Sindicato de Guias de Turismo (SINGTUR/PE), que lamentam o fato de o Governo de Pernambuco não ter atuado mais incisivamente:

\footnotetext{
Não fomos atendidos, em sua maioria, nos financiamentos bancários como o PRONAMPE, que infelizmente não atingiu seus objetivos pela enorme burocracia e liberou recursos apenas para cadastros aprovados ou que já gozavam de boa situação financeira bancária. Resultado: só atingiu $20 \%$ das empresas (ABRASEL/PE ${ }^{11}$ ).

Amparo quase nenhum, apenas duas cestas merenda. E as contas vencendo, empréstimos não foi viável porque juros altos, e alguns guias já negativados. [Precisamos de] Cestas básicas e auxílio emergencial do Estado, ao menos um salário mínimo ou empréstimo com 10 ou 12 mil, sem juros e 12 meses carência, para pagar em 24 parcelas, [como] aconteceu em Foz do Iguaçu e Espírito Santo (SINGTUR/PE ${ }^{12}$ ).
}

Acerca da expectativa de futuro, em curto e médio prazos, o setor do turismo de negócios, um dos que mais movimenta a cidade do Recife e, consequentemente, as cifras do turismo no Estado, não apresenta perspectiva de retorno, como pode ser visto na fala do representante do Recife Convention \& Visitors Bureau ${ }^{13}$ :

\footnotetext{
${ }^{9}$ Entrevista concedida no mês de novembro de 2020. (BRASIL, 2020)

${ }^{11}$ Entrevista concedida no mês de novembro de 2020.

${ }^{12}$ Entrevista concedida no mês de novembro de 2020.

${ }^{13}$ Entrevista concedida no mês de novembro de 2020.
}

${ }^{10}$ A MP 936, de 01 de abril de 2020, posteriormente convertida na Lei n ${ }^{\circ} 14.020$ de 2020, tratou da suspensão temporária de contratos e redução de jornada de trabalho. Por meio dela, empregadores puderam optar por não demitir seus empregados e adotar tal suspensão de contrato trabalhista, e, com isso, os encargos salariais poderiam ser reduzidos em até $70 \%$. 
“Em nosso planejamento está também o trabalho junto ao mercado de lazer, infelizmente o turismo de negócios não tem previsão de retomada".

Já o trade e o Sindicato de Guias apontam lacunas com relação a políticas públicas nesse período, compreendendo que o setor público deixou a desejar, conforme pode ser observado nas falas:

\footnotetext{
Não tivemos uma assistência devida, porque o turismo deixa uma boa arrecadação para Estado (SINGTUR/PE).

No estado, tivemos um maior envolvimento [em comparação ao município] pelo assessoramento e articulação da Secretaria de Desenvolvimento Econômico" (ABRASEL/PE).

O Governo Estadual pouquíssimas políticas, pouquíssima, quase zero, tá!?.[A ABIH/PE] Avalia como muita preocupação [a atuação governamental] porque eu acho que os governos precisam enxergar que o turismo tem uma função estratégica para o desenvolvimento de um município, de estado ou de um país. Ele movimenta 52 segmentos da economia e isso gera, traz riquezas, emprego, o turismo também emprega muito, tem um grande volume de empregos, então, eu acho que na hora que os governos entenderem isso o turismo do Brasil, de Pernambuco e de Recife serão melhores (ABIH/PE).
}

A se avaliar pelas entrevistas concedidas, percebe-se que as incertezas assolam o setor público, trade turístico e trabalhadores do setor. É notória a preocupação de como será, e em qual espaço de tempo, a retomada do turismo. Por outro lado, há de se reconhecer que as ações da SETUR/PE não pararam junto com o fluxo de turistas. Aparentemente, o trabalho continuou eficiente, mediante o contexto nacional e mundial do turismo.

\section{CONSIDERAÇÕES FINAIS}

O país do Carnaval não é mais o mesmo depois de conhecer a pandemia da COVID-19. Estamos em 2021, mas ainda vivendo a falta de perspectiva iniciada em 2020. A pandemia tem destruído vidas, e a ausência de uma condução federal, que sinalize para um esforço de mitigar a crise sanitária, faz com que cada Estado tente administrá-la por conta própria. É como se o Brasil deixasse de ser República: cada Estado negocia diretamente segundo seus interesses e capacidade de caixa. Voltamos 132 anos na História.

No caso do Nordeste, um Comitê foi criado e buscou assessorar os governos dos nove Estados na condução de políticas públicas. No entanto, a dificuldade de ação efetiva no sentido de um isolamento necessário para conter o vírus esbarra com a questão econômica. Como lidar com a população sem emprego e sem dinheiro?

Esse drama é particularmente vivido nas atividades relacionadas ao turismo, como esse artigo procurou demonstrar. Se, por um lado, o governo de Pernambuco buscou assertivamente implementar as recomendações do Consórcio Nordeste por meio da promulgação de decretos que restaram na suspensão de atividades, por outro, as entrevistas demonstraram que as ações implementadas não têm sido suficientes no aspecto econômico, o que tem gerado pressão por parte do trade para uma abertura gradual das atividades, a despeito das recomendações para um recrudescimento das restrições de circulação. 
As entrevistas sinalizaram, de um lado, as ações da SETUR/PE, que, dentro de suas possibilidades, tem buscado dinamizar o setor e trazer alternativas como o "Bora Pernambucar". Por outro lado, o trade e o SINGTUR/PE reclamam por maior apoio financeiro. No entanto, avalia-se que não se pode exigir isenções fiscais dos Estados se o Governo Federal não abrir mão da disciplina fiscal, lembrando que esta visa, sobretudo, à manutenção do pagamento de juros e spreads bancários via títulos do tesouro.

16 de fevereiro de 2021. O centro do Recife vazio. As ladeiras de Olinda, desertas. O setor de turismo sofre um duro baque, e não é dos tambores. Para além dos foliões, orquestras de frevo, agremiações, vendedores ambulantes e catadores de latinhas lamentam e choram a falta de recursos que, para muitos deles, durariam até o próximo Carnaval. A recente aprovação do auxílio emergencial do ciclo carnavalesco pelo Estado de Pernambuco trouxe algum alívio para os artistas e grupos culturais, mas o que dizer para os vendedores ambulantes e catadores de latinhas?

17 de fevereiro, Quarta-Feira de Cinzas. Sem o Bacalhau do Batata. A pandemia segue seu curso de morte, com recordes diários. A população à deriva e sem o ópio do carnaval para ao menos Ihe trazer conforto, mesmo que passageiro. "Tristeza não tem fim, felicidade sim", já dizia o poeta. Esse ano, não teve felicidade.

\section{REFERÊNCIAS}

ANR. Associação Nacional de Restaurantes. Nova pesquisa ANR e Galunion aponta alta no fechamento de bares e restaurantes na pandemia. 566. ed., n. 12 (Especial Coronavírus), 2020. Disponível em: https://anrbrasil.org.br/wpcontent/uploads/2020/08/news 566 .pdf. Acesso em: 26 fev. 2021.

ARAÚJO, L.; RODRIGUES, M. D. L. Modelos de análise das políticas públicas. Sociologia, problemas e práticas, n. 83, 2017, p. 11-35.

BRASIL. Medida Provisória no 936, de 01 de abril de 2020. Institui o Programa Emergencial de Manutenção do Emprego e da Renda e dispõe sobre medidas trabalhistas. Brasília, DF: Presidência da República, 2020. Disponível em:

http://www.planalto.gov.br/ccivil 03/ ato2019-2022/2020/mpv/mpv936.htm. Acesso em: 02 mar. 2020.

CLEMENTINO, M. do L. M. A atualidade e o ineditismo do Consórcio Nordeste. Boletim Regional, Urbano e Ambiental, n. 21, jul. dez. 2019, p. 165-174.

C4NE. Comitê Científico de Combate ao Coronavírus do Consórcio Nordeste. 2020. Disponível em: https://www.comitecientificone.com.br/c4ne/o-c4ne. Acesso em 19 fev.2021.

COVID-19: Coordenador de comitê científico defende lockdown no país: 'Situação absolutamente crítica'. Portal G1, 2021. Disponível em: https://g1.globo.com/ba/bahia/noticia/2021/01/05/covid-19-coordenador-do-comite-cientifico-do-consorcio-do-ne-defendelockdown-no-pais-situacao-e-absolutamente-critica.ghtml. Acesso em 20 fev.2021.

CULTURA.PE. Portal da Cultura Pernambucana. Carnaval de Pernambuco é marcado pela interiorização. 2020. Disponível em: http://www.cultura.pe.gov.br/canal/carnaval/carnaval-de-pernambuco-e-marcado-pela-interiorizacao/. Acesso em: 16 fev. 2021

DOURADO, Mona Lisa. Pernambuco perde 1,2 mil empresas ligadas ao turismo e 108,9 mil empregos formais no setor durante a pandemia. Jornal do Comércio. 2020. Disponível em: Acesso em: 20 fev. 2021.

GARCIA, D; PASSOS, U; TOLEDO, M. et al. Governadores fecham estradas e vetam ônibus de outros estados. Folha de São Paulo, 2020. Disponível em: <https://www1.folha.uol.com.br/cotidiano/2020/03/governadores-fecham-estradas-e-vetam-onibus-deoutros-estados.shtml>. Acesso em 20 fev. 2021. 
GOVERNADOR da BA divulga carta de repúdio ao processo de impeachment. Portal G1, 2015. Disponível em: <http://g1.globo.com/bahia/noticia/2015/12/governador-da-ba-divulga-carta-de-repudio-ao-processo-de-impeachment.html>. Acesso em: 19, fev e 2021

JATOBÁ, Matheus. Prefeitura do Recife registra queda de quase R\$ 900 milhões na arrecadação municipal. Folha PE. 2020. Disponível em: https://www.folhape.com.br/economia/recife-tem-perda-de-arrecadacao/172788/. Acesso em: 20 fev. 2021.

KIND, L.; CORDEIRO, R. Narrativas sobre a morte: a gripe espanhola e a covid-19 no Brasil. In: Psicologia \& Sociedade, n. 32, 2020.

MEIRELES, Marina. Sem carnaval, setor de turismo em Pernambuco espera queda de mais de $40 \%$ na taxa de ocupação de hotéis. Portal G1, 2021. Disponível em: https://g1.globo.com/pe/pernambuco/noticia/2021/02/16/sem-carnaval-setor-de-turismo-empernambuco-espera-queda-de-mais-de-40percent-na-taxa-de-ocupacao-de-hoteis.ghtml. Acesso em 20/02/21.

MINISTÉRIO DA ECONOMIA. Secretaria do Trabalho. Microdados do Cadastro Geral de Empregados e Desempregados - CAGED. Brasília, 2020. Disponível em: http://pdet.mte.gov.br/. Acesso em: 17 set. 2020.

MINISTÉRIO DA INFRAESTRUTURA. Secretaria da Aviação Civil (SAC). Banco de dados: voos nacionais e internacionais 2019/2020 disponibilizado pela SAC. Brasília, set. 2020.

MOROSINI, Luciana. Turismo se recupera em Pernambuco, mas ficará abaixo de 2019. Diário de Pernambuco. 2020. Disponível em: https://www.diariodepernambuco.com.br/noticia/economia/2020/12/turismo-se-recupera-em-pernambuco-mas-abaixo-de2019.html. Acesso em: 20 fev. 2021.

NOVAIS, Vinicius. Setor de alimentação fora do lar sofre com falta de capital de giro. PANROTAS. 2020. Disponível em: https://www.panrotas.com.br/hotelaria/alimentos-e-bebidas/2020/08/setor-de-alimentacao-fora-do-lar-sofre-com-falta-de-capitalde-giro 176086.html. Acesso em: 26 fev. 2021.

OLIVEIRA, Thamires. Carnaval do Recife registra público de 2 milhões de pessoas e bate recorde, diz prefeitura. 2020a. Disponível em: https://g1.globo.com/pe/pernambuco/carnaval/2020/noticia/2020/02/26/carnaval-do-recife-registra-publico-de-2-milhoes-depessoas-e-bate-recorde-diz-prefeitura.ghtml. Acesso em: 16 fev. 21.

OLIVEIRA, João José. Turismo demitiu 1 milhão na pandemia e só retoma em 2023, diz associação. Portal UOL. 2020. Disponível em: https://economia.uol.com.br/noticias/redacao/2021/02/20/turismo-so-recupera-perdas-depois-de-2023-diz-associacao-deoperadoras.htm?cmpid=copiaecola. Acesso em $20 \mathrm{fev} .2021$.

ORTIZ, Humberto Tomé. O coronavírus reescreve o turismo rural? Reinvenção, adaptação e ação no contexto latino-americano. Cenário: Revista Interdisciplinar em Turismo e Território. Vol.8, nำ14, pp. 55-73. Brasília, 2020.

PEREIRA, Tiago. Entregadores de aplicativos fazem segunda greve nacional neste sábado. Rede Brasil Atual, 2020. Disponível em: <https://www.redebrasilatual.com.br/trabalho/2020/07/entregadores-de-aplicativos-fazem-2a-greve-nacional-neste-sabado/>. Acesso em: 01 mar. 2021.

ROSSI, R. de C.; SILVA, S. A. da. O Consórcio do Nordeste e o federalismo brasileiro em tempos de Covid-19. In: Espaço e Economia: Revista Brasileira de Geografia Econômica, n. 18, 2020, p. 1-17. Disponível em: https://doi.org/10.4000/espacoeconomia.13776. Acesso em: 17 fev. 2021.

SEBRAE/ABRASEL. Pesquisa Situação e Perspectivas do setor de alimentação fora do lar. 2.ed, 2020. Disponível em: https://datasebrae.com.br/wp-content/uploads/2020/08/2a-Pesquisa-Sebrae-e-Abrasel-v6-resumo-atualizado.pdf. Acesso em: 26 fev. 2021.

SECRETÁRIO da fazenda de Pernambuco demonstra preocupaçao com fim do auxílio emergencial. Rádio Jornal de Pernambuco, 2021. Disponível em: <https://radiojornal.ne10.uol.com.br/noticia/2021/01/11/secretario-da-fazenda-de-pernambuco-demonstrapreocupacao-com-fim-do-auxilio-emergencial-201932>. Acesso em: 20 fev. 2021.

SILVA, J. B. D.; MUNIZ, A. M. V. Pandemia do Coronavírus no Brasil: impactos no território cearense. Espaço e Economia: Revista Brasileira de Geografia Econômica, n. 17, 2020, p. 1-20.

SOUZA, C. Políticas públicas: uma revisão da literatura. Sociologias, n. 16, 2020, p. 20-45.

VERISSIMO, Isabela. Carnaval 2020 em Olinda atrai 3,6 milhões de foliões, diz prefeitura. Portal G1, 2020b. Disponível em: https://g1.globo.com/pe/pernambuco/carnaval/2020/noticia/2020/02/27/carnaval-2020-em-olinda-atrai-36-milhoes-defolioes.ghtml. Acesso em: 16 fev.21. 